NFIS HOW30

X $553-72-491$ PREPRINT

NASATH $(-6-6)$

\title{
EQUATORIAL RADIUS OF THE EARTH: A DYNAMICAL DETERMINATION
}

\section{MOHAMMAD ASADULLAH KHAN}

(NASA-TH-X-66151) EQUATORIAL RADIUS OF

THE EARTH: A DYNAMTCAL DETERMINATION (NASA) $16 \mathrm{p} \mathrm{HC} \$ 3.00$

CSCL $08 \mathrm{~F}$

G3/13 Unclas

N73-15411

52596

GSFC

GOODARD SPACE FLIGHT CENTER

GREENBELT MARYLAND

Reproduced by

NATIONAL TECHNICAL

INFORMATION SERVICE

US Department of Commerce 
EQUATORIAL RADIUS OF THE EARTH:

A DYNAMICAL DETERMINATION

\author{
Mohammad Asadullah Khan* \\ Geodynamics Branch \\ NASA \\ Goddard Space Flight Center \\ Greenbelt, Maryland 20771
}

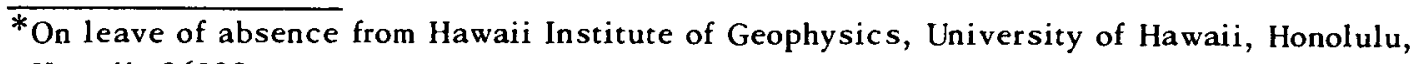
Hawaii, 96822.

\author{
GODDARD SPACE FLIGHT CENTER \\ Greenbelt, Maryland \\ i
}




\title{
PRECEDING PAGE BLANK NOT FILMED
}

\author{
EQUATORIAL RADIUS OF THE EARTH: \\ A DYNAMICAL DETERMINATION \\ Mohammad Asadullah Khan \\ Geodynamics Branch
}

\begin{abstract}
An interesting variation on the familiar method of determining the earth's equatorial radius $a_{e}$, from a knowledge of the earth's equatorial gravity is suggested. The value of equatorial radius thus found is $6378,142 \pm 5$ meters. The associated parameters are $\mathrm{GM}=3.986008 \pm .000004 \times 10^{20} \mathrm{~cm}^{3} \mathrm{sec}^{-2}$ which includes the relative mass of atmosphere $\simeq 10^{-6} \times \mathrm{GM}$, the equatorial gravity $\gamma_{\mathrm{e}}=978,030.9$ milligals (constrained in this solution by the Potsdam Correction of 13.67 milligals as the Potsdam Correction is more directly, or less indirectly, measurable than the equatorial gravity) and an ellipsoidal flattening of $f=1 / 298.255$.
\end{abstract}

\section{Preceding page blank}


CONTENTS

$\underline{\text { Page }}$

INTRODUCTION $\ldots \ldots \ldots \ldots \ldots \ldots \ldots \ldots \ldots \ldots \ldots \ldots \ldots \ldots \ldots \ldots \ldots \ldots \ldots \ldots$

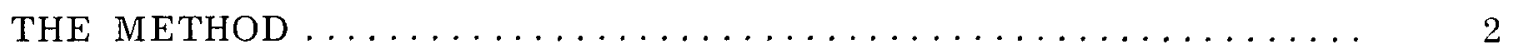

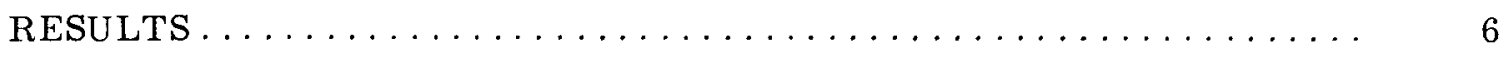

RECOMMENDATIONS $\ldots \ldots \ldots \ldots \ldots \ldots \ldots \ldots \ldots \ldots \ldots \ldots \ldots \ldots \ldots \ldots \ldots \ldots$

REFERENCES. . . . . . . . . . . . 10

ILLUSTRATIONS

Figure $\quad \underline{\text { Page }}$

1 Earth's Equatorial Radius $\mathrm{a}_{\mathrm{e}}$ as Function of $\mathrm{GM}$ and $\mathrm{d} \ldots \ldots . .7$

\section{TABLES}

$\underline{\text { Table }}$

$\underline{\text { Page }}$

1 Comparisons of the Recent Estimates of the Earth's Equatorial Radius a 


\section{EQUATORIAL RADIUS 'OF THE EARTH:}

\section{A. DYNAMICAL DETERMINATION:}

\section{INTRODUCTION}

The problem of determining the earth's equatorial radius $a_{e}$, consists of scaling a mean ellipsoid which best fits an accurately determined detailed geoid. The importance of the problem is well known in geodesy and many of the geodetic and geophysical applications of artificial earth satellites. Several theoretical approaches are available to solve the problem, namely, gravimetric methods (see for example, Heiskenan and Moritz, 1967), astrogeodetic methods (see for example, Fricke et al., 1965), dynamic and geometric satellite methods (see for example, Kaula, 1967; Anderle, 1967 or Veis, 1967) but their applications is limited by the density and precision of the available data required for the purpose.

In presatellite era a value of $\mathrm{a}_{\mathrm{e}}=6378,388$ meters, computed by Hayford (1909) from the isostatically reduced astrogeodetic data in the United States, was:: adopted to define the equatorial radius of the "international reference ellipsoid." The artificial earth satellite data analyses and space probe studies have indicated much smaller values (see, for example, Veis, 1967) ranging approximately between $\mathrm{a}_{\mathrm{e}}=6378,124$ meters and $\mathrm{a}_{\mathrm{e}}=6378,160$ meters, with the latest determi nations concentrated around a value of $\mathrm{a}_{\mathrm{e}}=6378,140$ meters approximately This can be seen from Table 1 which, by the way, is by no means anywhere near a complete listing of all the important work on the determination of $a_{e}$. 
Table 1

Comparisons of the Recent Estimates

of the Earth's Equatorial Radius a'

\begin{tabular}{|l|c|}
\hline \multicolumn{1}{|c|}{ Reference } & Equatorial Radius \\
\hline Vies (1965) & $\mathrm{a}_{\mathrm{e}}$ (meters) \\
Geodetic Reference System, 1967 & 6378,169 \\
Kaula, 1967 & 6378,160 \\
Present paper (atmospheric mass included) & 6378,153 \\
Present paper (atmospheric mass excluded) & 6378,144 \\
Veis (1965) & 6378,142 \\
Lambeck (1971) & 6378,142 \\
Rapp (1970) & 6378,140 \\
Strange et al. (1971) & 6378,138 \\
\hline
\end{tabular}

THE METHOD

The method suggested here stems from Khan's (1972) work showing that the Potsdam Correction d, can be expressed as

$$
\mathrm{d}=\left(\gamma_{\mathrm{P}}^{\mathrm{I}}-\gamma^{\mathrm{S}}\right)+\left(\Delta \mathrm{g}^{\mathrm{I}}-\Delta \mathrm{g}^{\mathrm{S}}\right)
$$

The quantities $\gamma$ and $\Delta \mathrm{g}$ are the theoretical gravity and gravity anomaly on the appropriate reference surface respectively. The superscript I denotes the 
international reference ellipsoid and the superscript $S$ the appropriate "satellite reference ellipsoid." The subscript P refers to the "Potsdam Gravity System." The theoretical gravity $\gamma$ on the surface of an arbitrary reference ellipsoid, is given by the well-known formula

$$
\gamma=\gamma_{e}\left(1+a_{2} \sin ^{2} \phi+a_{4} \sin ^{2} 2 \phi\right)
$$

where the equatorial gravity $\gamma_{e}$ is related to GM, $a_{e}$ and the flattening $f$ as

$$
G M=\gamma_{e} a^{2}(1-f)\left(1+\frac{3}{2} m+\frac{3}{7} m f+\frac{9}{4} m^{2}\right)
$$

and the coefficients $\alpha_{2}$ and $\alpha_{4}$ are given as

$$
a_{2}=-f+\frac{5}{2} m+\frac{1}{2} f^{2}-\frac{26}{7} m f+\frac{15}{4} m^{2}
$$

and

$$
\alpha_{4}=\frac{1}{8} \mathrm{f}^{2}-\frac{5}{8} \mathrm{mf}
$$

with

$$
m=\frac{\omega^{2} a^{3}(1-f)}{G M}
$$

Note that the above formulas are accurate only to the $O\left(f^{2}\right)$ as they neglect quantities $O\left(f^{3}\right)$.

The appropriate choice of $\gamma_{\mathrm{e}}, a_{2}$ and $\alpha_{4}$ in the above equations will yield $\gamma^{\mathrm{I}}$ or $\gamma^{\mathrm{s}}$ as the case may be. In practice, the quantity $\gamma_{\mathrm{P}}^{\mathrm{I}}$ is computed from the 
international gravity formula in which the value of equatorial gravity is tied to the Potsdam gravity system. Hence any error in the system is reflected in this quantity. The quantity $\gamma^{s}$ is computed from the socalled "satellite gravity formula" (not the "Gravity Formula 1967") in which the ellipsoid flattening is held fixed at $\mathrm{f}=1 / 298.255$ but GM and $\mathrm{a}_{\mathrm{e}}$ are treated as variables.

The gravity anomaly $\Delta \mathrm{g}$ is given by

$\Delta g=\frac{G M}{a_{e}^{2}} \sum_{n=2}^{\infty} \sum_{m=0}^{n}\left(\frac{a_{e}}{r}\right)^{n+2}(n-1)\left(\delta C_{n m} \cos m \lambda+\delta S_{r m} \sin m \lambda\right) P_{n m}(\sin \phi)$

where

$$
\begin{aligned}
& \delta C_{n m} \\
& \delta S_{n m}
\end{aligned}=\text { observed } \begin{aligned}
& C_{n m} \\
& S_{n m}
\end{aligned}-\text { reference } \begin{aligned}
& C_{n m} \\
& S_{n m}
\end{aligned}
$$

and other symbols have the usual meaning (see for example, Khan, 1969). In practice, however, only $\mathrm{C}_{20}$ and $\mathrm{C}_{40}$ are considered for the reference ellipsoid. Consequently all other $\delta \mathrm{C}_{\mathrm{nm}}$ and $\delta \mathrm{S}_{\mathrm{nm}}$ (except $\mathrm{n}=2$ and 4 ) equal the observed geopotential coefficients. The largest of the coefficient differences, involved in the computation of $\Delta \mathrm{g}^{\mathrm{I}}$ and $\Delta \mathrm{g}^{\mathrm{S}}$ or the difference $\Delta \mathrm{g}^{\mathrm{I}}-\Delta \mathrm{g}^{\mathrm{S}}$, does not exceed $10^{-5}$. Hence, neither of these quantities is sensitive to small changes in GM and $a_{e}$. Thus the sensitivity of $\gamma^{s}$ to small variations in GM or $a_{e}$ or more exactly the ratio $\mathrm{GM} / \mathrm{a}_{\mathrm{e}}^{2}$, on which the equatorial gravity $\gamma_{e}^{\mathrm{s}}$, used in computing $\gamma^{\mathrm{S}}$, is based makes the relation stated in Equation (1) highly useful as it can be utilized eventually to determine $a_{e}$.

Note from Equation (3) and the expression for $\mathrm{m}$ that the equatorial gravity $\gamma_{\mathrm{e}}$ is automatically fixed once the earth's rotational speed $\omega, \mathrm{GM}, \mathrm{a}_{\mathrm{e}}$ and the flattening 
$\mathrm{f}$ are defined. Of these quantities $\omega$ and $\mathrm{f}$ are well-determined. Of the remaining three i.e:, GM, $a_{e}$ and $\gamma_{e}$, knowledge of any two will determine the third uniquely. The quantity GM is independently determined from lunar and planetary probes and although these determinations still have a considerable uncertainty associated with them, GM is far more strongly determined than $\gamma_{e}$ or $a_{e}$. The quantity $\gamma_{\mathrm{e}}$ is not directly measurable and must be either derived theoretically from expressions involving $a_{e}$ (see Equation 3 ) which we wish to compute in this paper or from surface gravity data which does not form an adequate network. (This was true until recently but the situation is likely to change with the increased use of the portable free fall absolute gravity measuring equipment developed by Hammond and Faller, 1971).

This difficulty can be overcome, however, by controlling the value of equatorial gravity $\gamma_{\mathrm{e}}^{\mathrm{s}}$ (entering Equation (1) via $\gamma^{\mathrm{s}}$ ) through the Potsdam gravity correction $d$ as demonstrated in Equation (1). Because of the recent advances in electronic technology, the absolute gravity value at a particular site can be measured to an accuracy of a few parts in $10^{8}$ of absolute gravity g (Hammond and Faller, 1971). If such precise measurements could be made at the Potsdam site itself, the Potsdam gravity correction could be determined with the same precision. However, since no such measurements are available (in case they are, they have not been released to the scientific community), we can use indirect estimates of d made through highly accurate measurements of absolute gravity at sites previously tied to the Potsdam gravity system. Such measurements yield (Cook and Hammond, 1969) a value of approximately $d=13.67$ milligals which is probably correct to better than a milligal. 
The advantage of the method suggested in Equation (1) lies in the fact that the less cooperative equatorial gravity value is controlled through the Potsdam Correction d which is relatively more directly, or in fact less indirectly, measured. This is clearly shown by Equations (1) through(4). These equations also demonstrate that the method is equivalent to applying the Potsdam Correction to the equatorial gravity value $\gamma_{e}^{I}$ in the international gravity formula, projecting the corrected value onto an ellipsoid with a flattening of $\mathrm{f}=1 / 298.255$ and using the resulting value as a known parameter in Equation (3) to determine $a_{e}$. Thus Equation (1) is really an interesting variation on the well-known relation stated in Equation (3).

\section{$\underline{\text { RESULTS }}$}

The solution of Equation (1) is given in Figure 1 which shows plots of the earth's equatorial radius $a_{e}$ as functions of GM and Potsdam gravity correction $d$. The quantities $\gamma_{\mathrm{P}}^{\mathrm{I}}$ and $\Delta \mathrm{g}^{\mathrm{I}}$ are based on the well-known parameters of the international gravity formula and the international reference ellipsoid. The quantities $\gamma^{\mathrm{S}}$ and $\Delta \mathrm{g}^{\mathrm{S}}$ are based on an ellipsoidal flattening of $\mathrm{f}^{\mathrm{S}}=1 / 298.255$. The value of $\Delta \mathrm{g}^{\mathrm{I}}-\Delta \mathrm{g}^{\mathrm{S}}$ is kept compatible with the indicated values of GM and $\mathrm{a}_{\mathrm{e}}$, though small discrepancies in the value of GM and $a_{e}$ will not affect $\Delta g^{I}-\Delta g^{S}$ to the degree of accuracy (a few parts in $10^{8}$ of absolute gravity g) considered here. All the parameters used in computing $\gamma^{\mathrm{s}}$, which makes chief contribution to the changes in $d$ (see Equation (1) and Figure 1), are computed exactly from the appropriate values of GM and $a_{e}$.

As pointed out earlier, a well-accepted value of Potsdam correction (Cook and Hammond, 1969; Khan, 1972), obtained from the free fall determinations of 


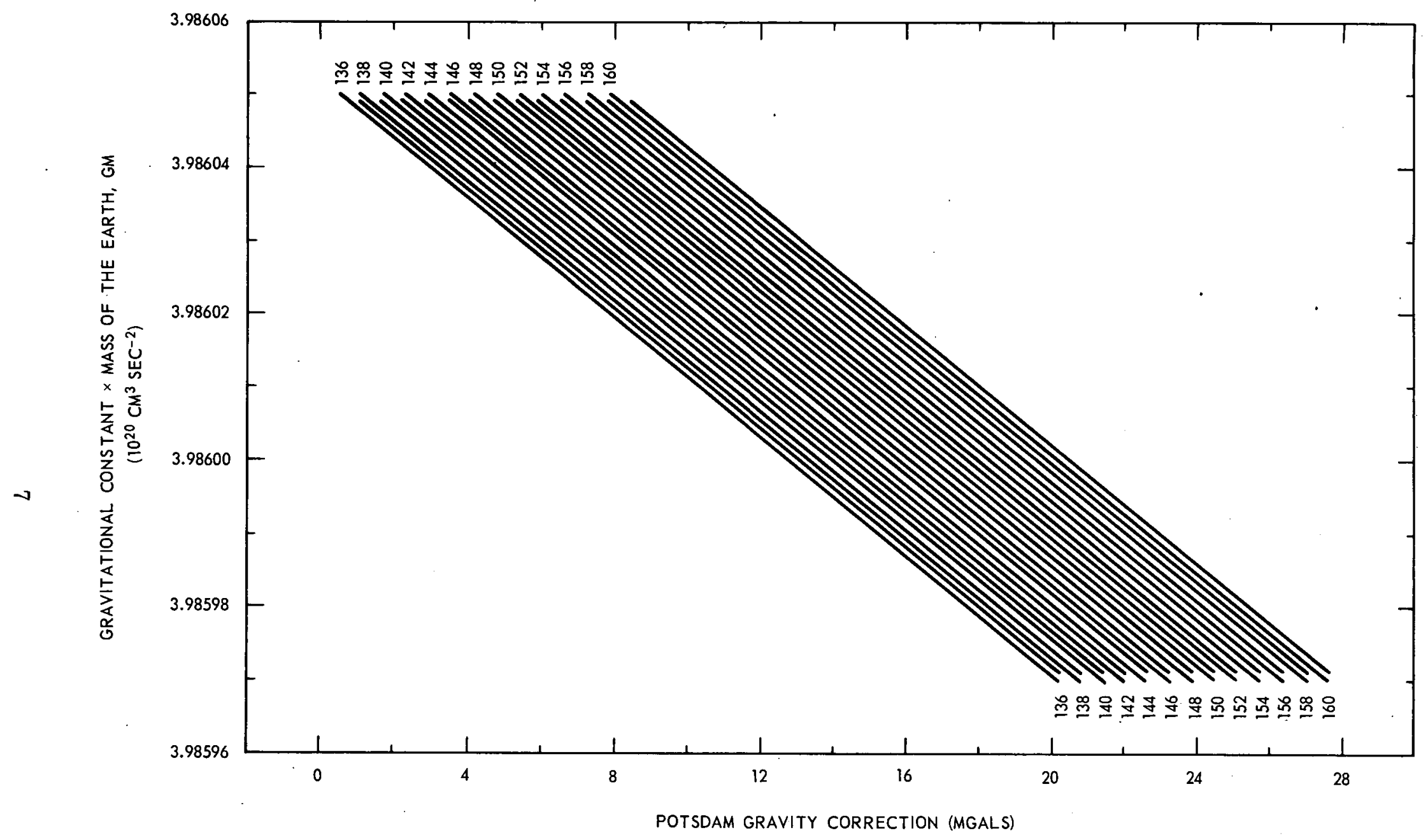

Figure 1. Earth's equatorial radius $a_{e}$ as function of GM and $d$. The labels on $a_{e}$ curves should be read with 6378 as prefix. For example, the rightmost slant curve has a value of 6378,161 meters and the leftmost 6378,136 meters. 
absolute gravity acceleration at various sites, is 13.67 milligals, with an accuracy probably better than a milligal. The most recent value of GM is $3.986008 \times$ $10^{20} \mathrm{~cm}^{3} \mathrm{sec}^{-2}$ (Esposito and Wong, 1972). Corresponding to these quantities, the value of equatorial radius is found to be $\mathrm{a}_{\mathrm{e}}=6378,144$ meters (to the nearest meter). The correction for the mass of the atmosphere reduces GM to 3.986005 $\times 10^{20} \mathrm{~cm}^{3} \mathrm{sec}^{-2}$ and the corresponding value of the equatorial radius is $\mathrm{a}_{\mathrm{e}}=$ 6378,142 meters (to the nearest meter). Compare it with $\mathrm{a}_{\mathrm{e}}=6378,160$ meters adopted by IUGG (Moscow, August 1971) on one extreme and with $\mathrm{a}_{\mathrm{e}}=6378,124$ meters (Strange et al., 1971) on the other extreme. Some of the important recent values of $a_{e}$ are listed in Table 1 .

The maximum error introduced by the approximations made in the second order theory used here is $5 \times 10^{-8}$ milligals. The error contributed by this factor in the determination of $a_{e}$, therefore, cannot exceed a few tenths of a meter. The chief sources of error are the uncertainties in GM, Potsdam Correction and the value of equatorial gravity in the International Reference System. Of these the uncertainty in GM is $\pm 4 \times 10^{14} \mathrm{~cm}^{3} \mathrm{sec}^{-2}$. This corresponds to an uncertaint $y$ of \pm 3.2 meters in the value of $\mathrm{a}_{\mathrm{e}}$. The maximum uncertainty in Potsdam Correction is not believed to exceed 1 milligal. This corresponds to a maximum uncertainty of 3 meters. Additional uncertainties could stem from some yet undetected systematic shift in the Potsdam gravity correction or the value of absolute gravity acceleration at the Potsdam site but it secms unlikely as the Potsdam correction obtained from various observation sites remains consistent. The tacit assumption made here is that the gravit! value obtained from the international gravity formula at the projection of the Potsdam site onto the 
reference ellipsoid is compatible with the old gravity value at the Potsdam site i.e., no error is assumed in the value of equatorial gravity $\gamma_{e}^{I}$ derived by Heiskenan (1928), except for the Potsdam Correction, and in the reduction of the absolute gravity value at the Potsdam site to the geoid. With this granted, the value of the equatorial radius of the best-fit earth ellipsoid is found to be $\mathrm{a}_{\mathrm{e}}=6378,144 \pm 5$ meters with the mass of the atmosphere included in GM and $\mathrm{a}_{\mathrm{e}}=6378,142 \pm 5$ meters with GM corrected for the mass of the atmosphere. The corresponding value of equatorial gravity $\gamma_{e}$ compatible with $a_{e}=6378,142$ meters is $\gamma_{\mathrm{e}}=978,030.9$ milligals (rounded to the nearest tenth of a milligal). Compare it to the equatorial gravity value of $978,031.1$ milligals (see for example, Veis, 1967) obtained from a much more extensive gravity coverage than was available to Heiskenan (1928). It is remarkable that $\gamma_{e}$ should display such a stability. It is also remarkable that if Heiskenan had the present values of $\mathrm{GM}, \mathrm{f}$ and d available to him in 1928 , he would have obtained a value of a very close to the modern values of the earth's equatorial radius.

\section{RECOMMENDATIONS}

The Recommended Geodetic Parameters are:

GM (corrected for mass

$$
\begin{aligned}
. \text { of the atmosphere) } & =3.986005 \pm .000004 \times 10^{20} \mathrm{~cm}^{3} \cdot \mathrm{sec}^{-2} \\
\mathrm{a}_{\mathrm{e}} & =6378,142 \pm 5 \text { meters } \\
\mathrm{f}^{-1} & =298.255 \pm .005 \\
\mathrm{~d} & =13.67 \pm 1 \text { milligals } \\
\gamma_{\mathrm{e}} & =978,030.9 \pm 2.5 \text { milligals }
\end{aligned}
$$




\section{REFERENCES}

1. R. Anderle, Geodetic parameter set NWL-5E-6 based on doppler satellite observations. The Use of Artificial Satellites for Geodesy, II (National Technical University, Athens, Greece (1967).

2. A. H. Cook and J. A. Hammond, The acceleration due to gravity at the National Physical Laboratory, Metrologia, 5, 141-142 (1969).

3. W. Fricke and several others, Report to the executive committee of the working group on the system of astronomical constants, Bull. Geod., No. 75, pp. 59-67 (1965).

4. J.F. Hayford, The figure of the earth and isostasy, from measurements in United States, U.S. Coast and Geodetic Survey (1909).

5. J. A. Hammond and J. E. Faller, Results of absolute gravity determinations at a number of sites, J. Geophys. Res. 76, 7850-7855 (1971).

6. W. A. Heiskenan, Ist die Erde ein dreiachsiges Ellipsoid? Gerlands Beitr. Geophys., v. 19, pp. 356-377.

7. W. A. Heiskenan and H. Moritz, Physical Geodesy, W. H. Freeman and Company (1967).

8. Kaula, W. M., Comparison and combination of satellites with other results for geodetic parameters, The Use of Artificial Satellites for Geodesy, II (National Technical University, Athens, Greece, 1967).

9. M. A. Khan, Potsdam Correction from the satellite determined geopotential, Nature Physical Sciences, vol. 239, 43-45 (1972). 
10. M. A. Khan, Figure of the Earth and mass anomalies defined by satellite orbit perturbations, Am. Geophys. Union Monograph No. 13, 293-304 (1969).

11. K. Lambeck, The relation of some major geodetic datums to a geocentric reference system, Bull. Geodes. 99 (1971).

12. W. E. Strange, S. F. Vincent, R. H. Berry and J. G. Marsh, A detailed gravimetric geoid for the United States, NASA Preprint No. X-552-71-219 (1971).

13. R. H. Rapp, Methods for the computation of geoidal undulations from potential coefficients, Ohio State University, Department of Geodetic Science Report No. 132 (1970).

14. G.Veis, the deflection of the vertical of major geodetic datums and the semimajor axis of the earth's ellipsoid as obtained from satellite observations, Space Research V (North Holland Pub. Co., Amsterdam, 1965).

15. G. Veis, The determination of the radius of the Earth and other geodetic parameters as derived from optical satellite data, Smith. Astrophys. Obsy. Rep. 264 (1967).

Additional and more extensive bibliographical references are given in the papers cited above. 


\section{LIST OF ILLUSTRATIONS}

Figure 1. Earth's equatorial radius $a_{e}$ as function of GM and $d$. The labels on $\mathrm{a}_{\mathrm{e}}$ curves should be read with 6378 as prefix. For example, the rightmost slant curve has a value of 6378,161 meters and the leftmost 6378,136 meters. 